\title{
Evaluation of Condylar and Ramal Asymmetry on Patients with Ectodermal Dysplasia
}

Tümen DS ${ }^{1}$, Callea $\mathbf{M}^{1}$, Yazgı AY ${ }^{1}$, Maglione $\mathbf{M}^{1}$, Yavuz $\mathrm{I}^{2^{*}}$, Montanari $\mathbf{M}^{2}$, Tümen $\mathrm{EC}^{2}$, Currà $\mathrm{MG}^{3}$ and Uysal $\mathrm{E}^{3}$

${ }^{1}$ Department of Orthodontics, Dicle University, Turkey

${ }^{2}$ Department of Pediatric Dentistry, Dicle University, Turkey

${ }^{3}$ Department of Technique Programs, Vocational High School, Turkey

"Corresponding author: Izzet Yavuz, Department of Pediatric Dentistry, Dicle University, Turkey, Tel: +90 412248 80; E-mail: izzetyavuz@hotmail.com

Rec date: Jan 29, 2014, Acc date: Jul 18, 2014, Pub date: Jul 20, 2014

Copyright: (c) 2014 Tümen DS, et al. This is an open-access article distributed under the terms of the Creative Commons Attribution License, which permits unrestricted use, distribution, and reproduction in any medium, provided the original author and source are credited

\begin{abstract}
Objectives: To compare the condylar, ramal, condylar-plus-ramal mandibular asymmetry of patients with ectodermal dysplasia and healthy control subjects with using cone beam computerized tomography (CBCT).

Materials and methods: CBCT of 9 patients ( 4 girls, 5 boys) with ectodermal dysplasia and 10 healthy control subjects ( 5 girls and 5 boys) with normal occlusion were included to our study. Mandibular asymmetry index measurements (condylar, ramal, and condylar-plus-ramal) were made on the CBCT. The paired samples t-test was used to establish statistically significant differences between the sides for condylar, ramal and condylar-plus-ramal height measurements. Independent $t$ test was used to determine possible statistically significant differences between the groups.
\end{abstract}

Results: There was no statistically significant difference between the right and left sides in condylar, ramal and condylar-plus-ramal height measurements of the patients with ectodermal dysplasia and normal occlusion sample. There was no statistically significant difference between the groups in asymmetry index measurements.

Conclusion: Patients with ectodermal dysplasia show similar condylar, ramal, condylar-plus-ramal measurements with healthy control subjects.

Keywords: Condylar and ramal asymmetry; Ectodermal dysplasia

\section{Introduction}

Ectodermal dysplasia (ED) is a large and complex group of disorders defined by the abnormal development of two or more structures derived from the ectodermal layer. As a result, HED patients mostly exhibit hypotrichosis, hypohidrosis, and cranial abnormalities. Patients often exhibit a smaller than normal face because of frontal bossing, and a depressed nasal bridge. Oral traits may express themselves as anodontia, hypodontia, and conical teeth. Anodontia also manifests itself by a lack of alveolar ridge development [1].

It has been proven that severe maxillary hypodontia in the permanent dentition, affects the cranial base and mandibular length in ED population [2]. In our study we decided to evaluate mandibular asymmetry due to hypodontia in ED patients (Figure 1).

\section{Aim}

Therefore our aim was to compare the condylar, ramal, condylarplus-ramal mandibular asymmetry of patients with ectodermal dysplasia and healthy control subjects with using cone beam computerized tomography (CBCT).

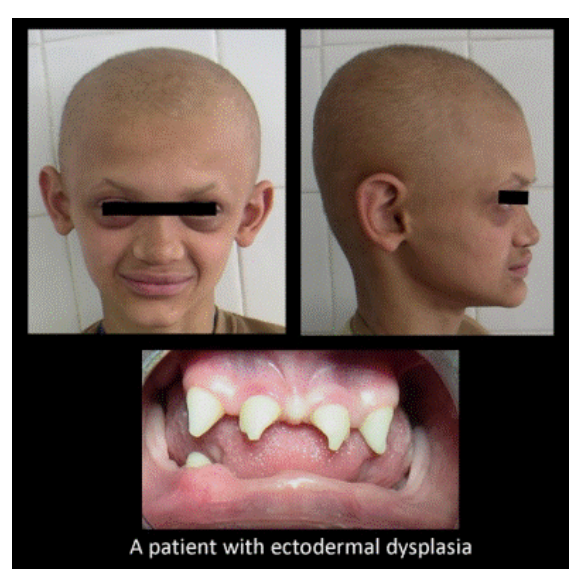

Figure 1: Maxillar and mandibular hypodontia in the permanent dentition in ED patients

\section{Material and Methods}

CBCT of 9 patients ( 4 girls, 5 boys) with ectodermal dysplasia and 10 healthy control subjects ( 5 girls and 5 boys) with normal occlusion were included to our study (Figure 2). 
Citation: Tümen DS, Callea M, Yazgi AY, Maglione M, Yavuz I, et al. (2014) Evaluation of Condylar and Ramal Asymmetry on Patients with Ectodermal Dysplasia. Dentistry 4: 249. doi:10.4172/2161-1122.1000249

Page 2 of 3

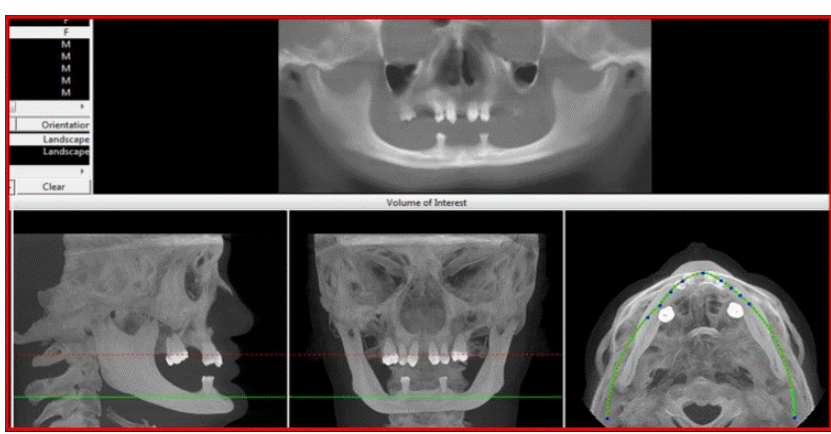

Figure 2: CBCT of a patient with ectodermal dysplasia
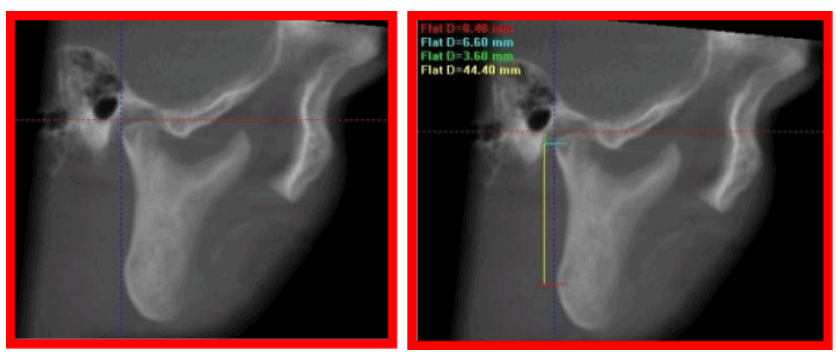

Figure 3: Mandibular asymmetry index measurements (condylar, ramal, and condylar-plus-ramal) were made on the CBCT

Reference lines were adjusted as following. Vertical line is passing from the most lateral points of condyle. Horizontal line is on the ramus tangent. Then, vertical distances of condyle and ramus were measured. According to Habets et al. [3], measurements were done and asymmetry index was calculated (Figure 3).

The paired samples t-test was used to establish statistically significant differences between the sides for condylar, ramal and condylar-plus-ramal height measurements. Independent $\mathrm{t}$ test was used to determine possible statistically significant differences between the groups.

\section{Results}

\begin{tabular}{|c|c|c|c|c|c|c|c|c|c|c|}
\hline & \multicolumn{5}{|l|}{ E.D. } & \multicolumn{5}{|c|}{ Normal } \\
\hline & \multicolumn{2}{|l|}{ Right } & \multicolumn{2}{|l|}{ Left } & & \multicolumn{2}{|l|}{ Right } & \multicolumn{2}{|l|}{ Left } & \\
\hline & mean & SD & mean & SD & $p$ & mean & SD & mean & SD & $\mathrm{p}$ \\
\hline Condylar & & & & & NS & & & & & NS \\
\hline Ramal & & & & & NS & & & & & NS \\
\hline Condylar + Ramal & & & & & NS & & & & & NS \\
\hline
\end{tabular}

Table 1: Statistically side comparisons of 2 groups

There was no statistically significant difference between the right and left sides in condylar, ramal, and condylar-plus-ramal height measurements of the patients with ectodermal dysplasia and normal occlusion sample. There was no statistically significant difference between the groups in asymmetry index measurements (Table 1 and 2).

\begin{tabular}{|l|l|l|l|l|}
\hline Asymmetry Index & Group & Mean & SD & $\mathbf{p}$ \\
\hline \multirow{2}{*}{ CAI } & E.D. & 6,909 & 6,1475 & \multirow{2}{*}{ NS } \\
\cline { 2 - 4 } & NORMAL & 3,874 & 3,6265 & \\
\hline \multirow{2}{*}{ RAI } & E.D. & 1,587 & 1,1416 & \multirow{2}{*}{ NS } \\
\cline { 2 - 4 } & NORMAL & 2,174 & 1,4654 & \\
\hline
\end{tabular}

\begin{tabular}{|l|l|l|l|l|}
\hline CRAI & E.D. & 1,668 & 1,6199 & \multirow{2}{*}{ NS } \\
\cline { 2 - 4 } & NORMAL & 2,070 & 1,0870 & \\
\hline
\end{tabular}

NS- not significant, CAl- condylar asymmetry index, RAI- ramal asymmetry index, CRAl- condylar plus ramal asymmetry index

Table 2: Descriptive statistics and comparisons of mandibular asymmetry index values of the 2 groups

\section{Discussion}

The first aim of this study was to compare the condy, ramal, condylar-plus-ramal mandibular asymmetry of patients with ectodermal dysplasia and sound patients. 
Citation: Tümen DS, Callea M, Yazgi AY, Maglione M, Yavuz I, et al. (2014) Evaluation of Condylar and Ramal Asymmetry on Patients with Ectodermal Dysplasia. Dentistry 4: 249. doi:10.4172/2161-1122.1000249

Page 3 of 3

Previous studies evaluated mandibular asymmetry in various malocclusion patterns [4-6].

These studies made their measurements on posteroanterior radiographies but they had some limitations of methodology and reliability [7].

Literature suggests that $\mathrm{CBCT}$ is more accurate in image description. In the present study CBCT was used in order to the reduce visualization techniques errors [8].

Several studies documented asymmetries in condylar position in the fossa in unilateral posterior crossbite children $[9,10]$. There was no significant difference between the sides in in our results. This contrasting result might be caused by sample selection. Most of our patients don't have unilateral posterior crossbite.

Sezgin et al. [11] found that Class II/1 malocclusion has a significant effect on condylar asymmetry index when compared to Class II/2 and Class III malocclusion and normal occlusion types.

Our findings contradict with this study. In effect it is known that one of the main oral features of ED children is Class III malocclusion [1].

\section{Conclusion}

In effect it is known that one of the main oral features of ED children is Class III malocclusion but at the patients with ectodermal dysplasia show similar condylar, ramal, condylar-plus-ramal measurements with healthy control subjects.

This aspect has need to further studies for confirm results obtained in the present study.

\section{References}

1. Yavuz İ, Başkan Z, Ülkü R, Dulgergil TC, Dari O, et al. (2006) Ectodermal dysplasia: Retrospective study of fifteen cases. Arch Med Res 37: 403-409.

2. Johnson EL, Roberts MW, Guckes AD, Bailey LJ, Phillips CL, et al. (2002) Analysis of craniofacial development in children with hypohidrotic ectodermal dysplasia. Am J Med Genet 112: 327-334.

3. Habets LLMH, Bezuur JN, Naeiji M, Hansson TL (1988) The orthopantomograph, an aid in diagnosis of temporomandibular joint problems. II. The vertical symmetry. J Oral Rehabil 15: 465-471.

4. Miller VJ, Smidt A (1996) Condylar asymmetry and age in patients with an Angle's Class II division 2 malocclusion. J Oral Rehabil 23: 712-715.

5. Kurt G, Uysal T, Sisman Y, Ramoglu SI (2008) Mandibular asymmetry in Class II subdivision malocclusion. Angle Orthod 78: 32-37.

6. Saglam AM (2003) The condylar asymmetry measurements in different skeletal patterns. J Oral Rehabil 30: 738-742.

7. Uysal T, Şişman Y, Kurt G, Ramoğlu Sİ (2009) Condylar and ramal vertical asymmetry in unilateral and bilateral posterior crossbitepatients and a normal occlusion sample. Am J Orthod Dentofacial Orthop 136: 37-43.

8. De Vos W, Casselman J, Swennen GR (2009) Cone-beam computerized tomography $(\mathrm{CBCT})$ imaging of the oral and maxillofacial region: a systematic review of the literature. Int J Oral Maxillofac Surg 38: 609-625.

9. Myers DR, Barenie JT, Bell RA, Williamson EH (1980) Condylar position in children with functional posterior crossbite before and after crossbite correction. Pediatr Dent 2: 190-194.

10. Hesse K, Artun J, Joondeph DR, Kennedy DB (1997) Changes in condyle position and occlusion associated with maxillary expansion for correction of functional unilateral posterior crossbite. Am J Orthod Dentofacial Orthop 111: 410-418.

11. Sezgin OS, Celenk P, Arıcı S (2007) Mandibular asymmetry in different occlusion patterns. Angle Orthod 77: 803-807. 